Case Report

\title{
Acute Onset Pancreatitis in the Third Trimester of Pregnancy in HBV Carrier Women Taking Telbivudine for Blocking Mother-to-Infant Transmission
}

\author{
Hao-feng Xiong ${ }^{1}$, Jing-yuan Liu ${ }^{1}$, Hao-dong Cai ${ }^{2}$ and Jun Cheng ${ }^{2}$
}

Acute pancreatitis in pregnancy (APIP) is rare and the reasons for APIP are biliary disease and congenital or acquired hypertriglyceridemia, which could occur during any trimester but more than $50 \%$ cases happened during the third trimester. In this report, one case of a young pregnant woman, a HBV carrier in her 37th week $+5 \mathrm{~d}$ of gestation, was admitted to Emergency Department due to acute abdominal pain, vomiting and diarrhea. The patient was in antiretroviral treatment with telbivudine from 28 weeks of gestation to prevent motherto-child transmission of HBV. Laboratory tests demonstrated hypertriglyceridemia, abdominal computed tomography scan revealed peripancreatic edema. Hyperlipidemic pancreatitits was primary diagnosed and the patient was admitted to the intensive care unit. Considering the possible role in the pathogenesis of pancreatitis, telbivudine was interrupted after birth giving. After supportive treatment, her condition gradually improved. Since it is the first description of APIP during treatment with telbivudine, the association between pregnancy, hyperlipidemia, telbivudine and acute pancreatitis has been well investigated.

Key words: Acute pancreatitis; Pregnancy; HBV carrier; Hyperlipidemia; Telbivudine

A cute pancreatitis in pregnancy (APIP) is a rare but serious condition; it occurs in approximately 1 in 1000 to 3 in 10000 births. ${ }^{1-3}$ The most common reasons for APIP are biliary disease and congenital or acquired hypertriglyceridemia, which could occur during any trimester but more than $50 \%$ cases occurred during the third trimester. ${ }^{4}$

The management of chronic hepatitis B (CHB) during pregnancy remains a challenge and contains a variety of maternal-fetal care. Despite the standard immunoprophylaxis, a portion of infants of highly viremic mothers remain infected with hepatitis $B$ virus (HBV). It has suggested that antiviral therapy in the third trimester can prevent immunoprophylaxis failure. $^{5}$

\footnotetext{
${ }^{1}$ ICU, Beijing Ditan Hospital, Capital Medical University, Beijing 100015, China; ${ }^{2}$ Hepatology clinic, Beijing Ditan Hospital, Capital Medical University, Beijing 100015, China

This research was sponsored by the Young Doctor Research Foundation in Beijing Ditan Hospital, Capital Medical University (2011-06) and the Basic Research and Clinical Research Collaboration Foundation in Capital Medical University (12JL84).

Co-author: Jing-yuan Liu

Correspondence: Jun Cheng, E-mail: jun.cheng.ditan@gmail.com
}

Telbivudine (LdT), a nucleoside analogue, is a pregnancy category B antiviral drug. In recent years, increasing reports have focused on the safety of LdT treatment for CHB in the third trimester of pregnancy to block mother-to-infant transmission (MTIT) of $\mathrm{HBV}$; there's evidence showing that LdT treatment is safe and effective for chronic HBV-infected pregnant mothers in the entire pregnancy. ${ }^{6-8}$

According to the literature and Food and Drug Administration records, there are only two cases of male HBV patient taking telbivudine who had acute pancreatitis recently. ${ }^{9}$ In this article, one case of acute onset pancreatitis occurred in a female HBV carrier in the third trimester of pregnancy taking telbivudine to block mother-to-infant transmission was reported.

\section{CASE PRESENTATION}

The patient was admitted in the 37 th week $+5 \mathrm{~d}$ of gestation with severe acute mid-epigastria pain associated with diarrhea, vomiting, fever, general malaise for one day. She had no history of gestational 
diabetes mellitus, alcohol use, oral contraception pills, gallstones, pancreatitis or drug intake. She had no history of pancreatitis. This HBV carrier has ten years history of HBV infection. Her liver function was normal, ALT 24.1 U/L, AST 39.8 U/L and the HBVDNA was $1.06 \times 10^{8}$ copies $/ \mathrm{ml}$ at the 2 nd trimester, then she received telbivudine at the 28 th week of pregnancy to prevent mother-to-child transmission of HBV. When arriving the Emergency Department, she appeared to be dehydrated and suffering from abdominal pain radiating to back. The patient's height and weight were $165 \mathrm{~cm}$ and $74 \mathrm{~kg}$, respectively. Blood pressure, pulse and temperature were $120 / 70 \mathrm{~mm} \mathrm{Hg}$, 112 beats/min and $38.5^{\circ} \mathrm{C}$, respectively. Physical examination showed epigastria tenderness. Lab examinations found that blood pancreatic amylase was $449 \mathrm{U} / \mathrm{L}$ (normal range was $0-115 \mathrm{U} / \mathrm{L}$ ) and urine amylase was $6200 \mathrm{U} / \mathrm{L}$ (normal range was 0-600 U/L), blood lipase level was $633 \mathrm{U} / \mathrm{L}$ (normal range was 0-60 U/L). Total cholesterol was normal $(5.12 \mathrm{mmol} / \mathrm{L})$ and triglycerides was $2.49 \mathrm{mmol} / \mathrm{L}$. Blood gases analysis showed compensatory metabolic acidosis $(\mathrm{pH} 7.377$; bicarbonate $18.0 \mathrm{mmol} / \mathrm{L}$; BE- $8 \mathrm{mmol} / \mathrm{L}$, lactate 1.6 $\mathrm{mmol} / \mathrm{L}$ ). Based on clinical data, acute pancreatitis was suspected. Hypertriglyceridemia-induced pancreatitis (HLP) was suspected and the patient was admitted to the intensive care unit (ICU). In case of fetal distress and advancing preterm labor, a cesarean delivery was performed under spinal anesthesia, and the patient delivered a healthy $2850 \mathrm{~g}$ female infant. After delivery, abdominal enhanced computed tomography (CT) scan revealed that the pancreas appeared diffusely enlarged, density decreased and had peripancreatic effusion (Figure 1). There was no stone in the biliary tract.

After treatment in ICU, metabolic acidosis were immediately corrected and $6 \mathrm{~h}$ after ICU admission, arterial $\mathrm{pH}$, serum bicarbonate, lactate and glucose level were within normal limits $(\mathrm{pH} 7.36$; bicarbonate $24.2 \mathrm{mmol} / \mathrm{L}$; lactate $0.4 \mathrm{mmol} / \mathrm{L}$; whole blood glucose $83 \mathrm{mg} / \mathrm{dl}$ ). In addition, parenteral calcium gluconate, pancreatic enzyme inhibitor, empirical antibiotic therapy (Imipenem $1 \mathrm{~g} \mathrm{IV}$ ) and gastric protector (omeprazole $20 \mathrm{mg}$ IV daily) were administered.

Telbivudine was interrupted due to its possible role in HLP pathogenesis. Ionized and total serum calcium, hemoglobin, whole blood glucose, urea and creatinine levels, blood gases were serially measured and the results were all within normal limits. Abdominal pain and fever disappeared within 3 days. Imipenem was stopped on the fifth day. On the 7th day, CT scan showed resolution of pancreatic edema; electrophoresis did not show any preexisting familiar lipoprotein abnormalities and the patient was discharged to normal ward on the 12th day. She

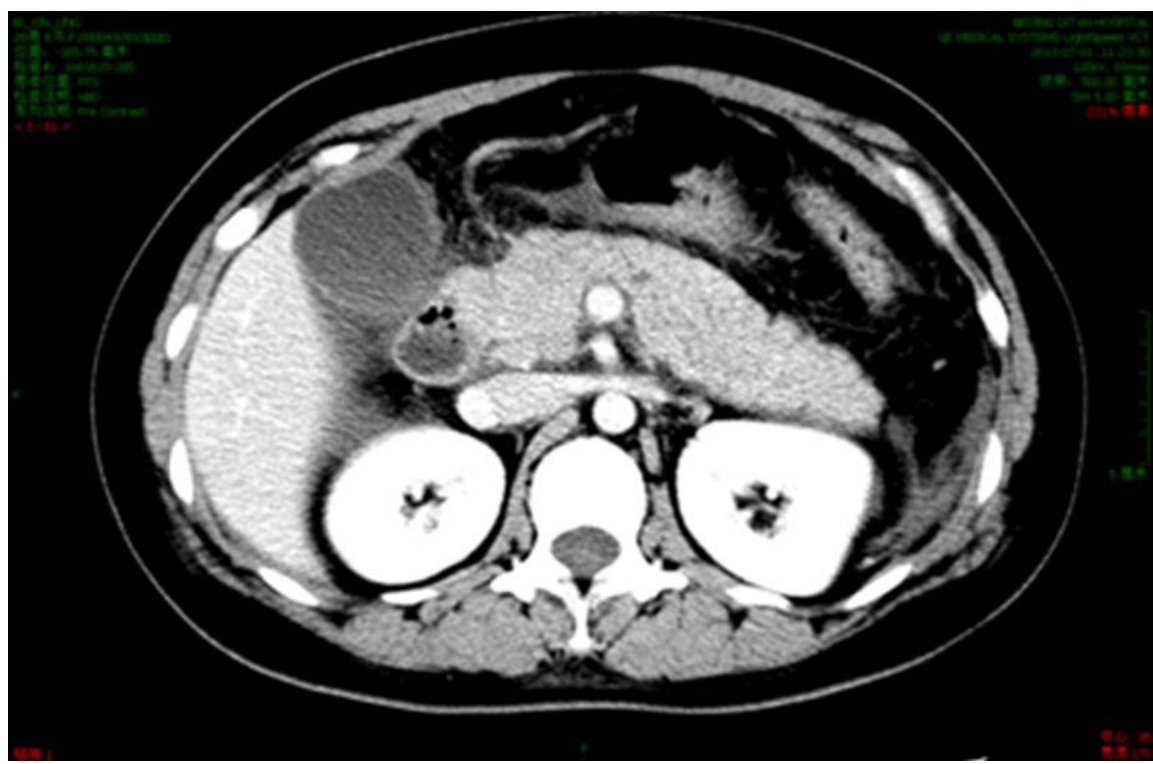

Figure 1. Enhanced computed tomography.

Notes: The pancreas appeared diffusely enlarged, density decreased and had peripancreatic effusion. 
was followed-up for 6 months and no recurrences of hypertriglyceridemia or pancreatic damage were observed.

\section{DISCUSSION}

This report illustrates one case of acute pancreatitis in a HBV infected pregnant patient with telbivudine therapy. Since it is the first description of APIP during treatment with telbivudine, the association between pregnancy, acute pancreatitis (AP), hyperlipidemia and telbivudine has been well investigated.

APIP should be considered in the differential diagnosis of upper quadrant abdominal pain with or without nausea and vomiting. ${ }^{10,11}$ The relationship between AP and pregnancy is not quite clear. It's generally believed that APIP results from a synergy effect of several factors.

Currently, there are two principal mechanisms of APIP. One is biliary pancreatitis derived from the disease of cholecystitis and biliary tract. According to the related statistics, the incidence of gallstone in pregnancy is between $2.5 \%$ and $4.2 \% .{ }^{12} \mathrm{Li}$ et al reviewed the cases in Sixth People's Hospital Affiliated to Shanghai Jiao Tong University between 2005 and 2010. They found the major etiology of APIP was due to gallstone and cholecystitis. ${ }^{13}$ Another pathogenesis is hyperlipidemia in pregnancy that can result in the microcirculation disturbance and hyperlipoproteinemia. As a consequence, a number of fatty acid derived from degradation of blood triglyceride by high pancreatic lipase may cause pancreatic ischemia and necrosis due to capillary thrombus and breakdown of vessel wall. The placental lactogen produced by syneytiotrophoblast in pregnancy can disassociate fat notably and release a sum of free fatty acids which cause acute adipose infiltration of acinar cells and fat embolism of pancreatic vessel that lead to pancreatitis and necrosis. ${ }^{14,15}$ In addition, SAP could be raised from Odd's sphincterismus resulted from high level of mental stress in pregnancy. ${ }^{16}$ It is augmented that the uterus compresses pancreatic and biliary duct is a key factor for the development of APIP.

Hypertriglyceridemia is a known cause of acute pancreatitis. Hypertriglyceridemia may be primary, such as in chylomicronemia syndrome, or secondary to alcohol abuse, diabetes mellitus, estrogen use as well as pregnancy. Hypertriglyceridemia-induced pancreatitis during pregnancy has been reported previously. The clinical course and treatment of pancreatitis due to hypertriglyceridemia is similar to that of pancreatitis of other causes. Family history of lipid abnormalities should be obtained, and an attempt to identify secondary causes should be made. A serum triglyceride level of more than $1000 \mathrm{mg} / \mathrm{dl}$ is an identifiable risk factor. Reduction of triglyceride to less than $1000 \mathrm{mg} / \mathrm{dl}$ could effectively prevent further episodes of pancreatitis. ${ }^{17,18}$ Acute pancreatitis of any cause may result in mild secondary hyperlipidemia in up to $50 \%$ of patients affected: this condition should not be confused with the marked hypertriglyceridemia $(>1000 \mathrm{mg} / \mathrm{dl})$ that is needed to cause HLP. ${ }^{19}$ HLP pathogenesis is often related to a pre-existing lipoprotein abnormality (hyperlipidemia type I, IV and V, defined according to Frederickson's classification $^{20}$ ) associated to a second risk factor such as diabetes mellitus, alcohol abuse, drugs such as diuretics, beta-blockers, estrogens that may cause an increase in triglycerides to a significant level resulting in pancreatitis. ${ }^{19}$

HLP pathogenesis is not taken into account in our patient: the highest level of triglycerides was only $2.49 \mathrm{mmol} / \mathrm{L}$ and it was within normal range in pregnancy. She did not present any evidence of congenital error of metabolism or familial hyperlipidemia and electrophoresis did not show any lipoprotein abnormalities, moreover the serum levels of triglycerides measured six and three months earlier and during all the follow-up period were within normal limits. Our patient was not on any medication which would have potentially involved in HLP pathogenesis.

As described by Chaudari et al, nucleoside inhibitors are likely to cause acute pancreatitis, these kinds of drugs are also involved in important alteration on lipidic and glucidic metabolism. ${ }^{21}$ It has been postulated that nucleoside analogue medication may be responsible for a wide spectrum of clinical presentations related to mitochondrial toxicity caused by inhibition of DNA gamma polymerase. ${ }^{22}$

Sarner et al reported two HIV-1 positive women in the third trimester of pregnancy who presented acute lactic acidosis and acute pancreatitis, respectively. Both of them had been stable with regimens containing stavudine and didanosine for at least 2 years before their acute onset. ${ }^{23}$

Hyperamylasemia is a well-known complication after using lamivudine, and serum concentrations of amylase after 6 to 12 months of treatment were higher than those before treatment. Previous publications have indicated cases of lamivudine 
induced pancreatitis. ${ }^{24-26}$ Not only lamivudine, but also entecavir and adefovir dipivoxil had been reported to cause acute pancreatitis. ${ }^{27,28}$

In a lager clinical study, the most common adverse reactions of telbivudine were headache, fatigue, dizziness and nausea, whereas the most common laboratory abnormality (Grade 3 or 4 laboratory abnormalities) were increased alanine aminotransferase $(3.7 \%)$, lipase $(1.8 \%)$, amylase $(0.1 \%)$, absolute neutrophil count $(1.9 \%)$ and platelet count $(0.7 \%) .{ }^{29}$ According to the literature and Food and Drug Administration records, there are only two male HBV patients taking telbivudine had acute pancreatitis recently.

Our patient had received a 3 months treatment with telbivudine preceding the actual AP episode. Therefore, telbivudine was the most reasonable mechanism involved in the genesis of acute pancreatitis in this patient.

In conclusion, by presenting this case report, serious attention should be paid on the potential role of telbivudine in causing acute pancreatitis in pregnancy.

\section{REFERENCES}

1. Pitchumoni CS, Yegneswaran B. Acute pancreatitis in pregnancy. World J Gastroenterol 2009;15:5641-5646.

2. Nanda S, Gupta A, Dora A. Acute pancreatitis: a rare cause of acute abdomen in pregnancy. Arch Gynecol Obstet 2009;279:577-578.

3. Stimac D, Stimac T. Acute pancreatitis during pregnancy. Eur J Gastroenterol Hepatol 2011;23:839-844.

4. Beaufils M. Medical complications of pregnancy: numerous factors. Rev Prat 2003;53:1875-1877.

5. Pan CQ, Lee HM. Antiviral therapy for chronic hepatitis B in pregnancy. Semin Liver Dis 2013;33:138-146.

6. Liu MH, Sheng YJ, Liu JY, Hu HD, Zhang QF, Ren H. Efficacy of telbivudine on interruption of hepatitis B virus vertical transmission: a meta-analysis. Ann Saudi Med 2013;33:169-176.

7. Guclu E, Karabay O. Choice of drugs in the treatment of chronic hepatitis B in pregnancy. World J Gastroenterol 2013;19:1671-1672.

8. Liu M, Cai H, Yi W. Safety of telbivudine treatment for chronic hepatitis B for the entire pregnancy. J Viral Hepat 2013;20 Suppl 1:65-70.

9. Food and Drug Administration, Telbivudine and Pancreatitis Acute [EB/OL] (2013-8-15). http://www.drugcite.com/indi/?q= TELBIVUDINE\& $\mathrm{s}=\& \mathrm{a}=\& \mathrm{i}=$ PANCREATITIS + ACUTE\#show RxAdverseEvents.

10. Papadakis EP, Sarigianni M, Mikhailidis DP, Mamopoulos A, Karagiannis V. Acute pancreatitis in pregnancy: an overview. Eur J Obstet Gynecol Reprod Biol 2011;159:261-266.

11. Geng Y, Li W, Sun L, Tong Z, Li N, Li J. Severe acute pancreatitis during pregnancy: eleven years experience from a surgical intensive care unit. Dig Dis Sci 2011;56:3672-3677.
12. Zeng YL, Li LA. Clinical analysis of 6 cases of mid-pregnancy complicated with acute pancreatitis. Zhong Hua Fu You Lin Chuang Yi Xue Za Zhi (Chin) 2007; 3:96-97.

13. Li HP, Huang YJ, Chen X. Acute pancreatitis in pregnancy: a 6-year single center clinical experience. Chin Med J (Engl) 2011;124:2771-2775.

14. Vandenbroucke L, Seconda S, Lassel L, Le Bouar G, Poulain P. Acute pancreatitis induced by major hypertriglyceridemia during pregnancy. A case report. J Gynecol Obstet Biol Reprod (Paris) 2009;38:436-439.

15. Crisan LS, Steidl ET, Rivera-Alsina ME. Acute hyperlipidemic pancreatitis in pregnancy. Am J Obstet Gynecol 2008;198:57-59.

16. Li J, Wang R, Tang C. Somatostatin and octreotide on the treatment of acute pancreatitis-basic and clinical studies for three decades. Curr Pharm Des 2011;17:1594-1601.

17. Okura Y, Hayashi K, Shingu T, Kajiyama G, Nakashima Y, Saku K. Diagnostic evaluation of acute pancreatitis in two patients with hypertriglyceridemia. World J Gastroenterol 2004;10:3691-3695.

18. Athyros VG, Giouleme OI, Nikolaidis NL, Vasiliadis TV, Bouloukos VI, Kontopoulos AG, et al. Long-term follow-up of patients with acute hypertriglyceridemia-induced pancreatitis. J Clin Gastroenterol 2002;34:472-475.

19. Yadav D, Pitchumoni CS. Issues in hyperlipidemic pancreatitis. J Clin Gastroenterol 2003;36:54-62.

20. Al-Humoud H, Alhumoud E, Al-Hilali N. Therapeutic plasma exchange for acute hyperlipidemic pancreatitis: a case series. Ther Apher Dial 2008;12:202-204.

21. Chaudhari S, Park J, Anand BS, Pimstone NR, Dieterich DT, Batash S, et al. Acute pancreatitis associated with interferon and ribavirin therapy in patients with chronic hepatitis C. Dig Dis Sci 2004;49:1000-1006.

22. Brinkman K, ter Hofstede HJ, Burger DM, Smeitink JA, Koopmans PP. Adverse effects of reverse transcriptase inhibitors: mitochondrial toxicity as common pathway. AIDS 1998; 12:1735-1744.

23. Sarner L, Fakoya A. Acute onset lactic acidosis and pancreatitis in the third trimester of pregnancy in HIV-1 positive women taking antiretroviral medication. Sex Transm Infect 2002; 78:58-59.

24. Chen $\mathrm{CH}$, Changchien CS, Lu SN, Wang JH, Hung CH, Lee $\mathrm{CM}$. Lamivudine treatment for recurrent pancreatitis associated with reactivation of chronic B hepatitis. Dig Dis Sci 2002; 47:564-567.

25. Tuon FF, Guastini CM, Boulos MI. Acute pancreatitis associated with lamivudine therapy for chronic B hepatitis. Braz J Infect Dis 2008; 12:263.

26. Soylu AR, Dokmeci G, Tezel A, Cakir B, Umit H, Karahan $\mathrm{N}$, et al. Lamivudine-induced acute pancreatitis in a patient with decompensated HBV-related chronic liver disease. J Clin Gastroenterol 2004; 38:134.

27. Durval A, Zamidei L, Bettocchi D, Luzzio M, Consales G. Hyperlipidemic acute pancreatitis: a possible role of antiretroviral therapy with entecavir. Minerva Anestesiol 2011; 77:1018-1021.

28. Weber A, Carbonnel F, Simon N, Kantelip B, Coaquette A, Mantion G, et al. Severe acute pancreatitis related to the use of adefovir in a liver transplant recipient. Gastroenterol Clin Biol 2008:32:247-249.

29. Lai CL, Gane E, Liaw YF, Hsu CW, Thongsawat S, Wang Y, et al. Telbivudine versus lamivudine in patients with chronic hepatitis B. N Engl J Med 2007;357:2576-2588. 